\title{
O tópico discursivo em novos contextos de interação
}

\author{
Mônica Lopes Smiderle de Oliveira* \\ Maria da Penha Pereira Lins ${ }^{* *}$ \\ Rivaldo Capistrano Souza Junior ${ }^{* * *}$ \\ Aline Souza de Lima ${ }^{* * *}$ \\ Rosana de Castro Januário Murayama ${ }^{* * * *}$
}

Resumo: Este trabalho tem por intuito observar como o tópico discursivo pode ser visto nos novos contextos de interação da internet. O texto nesse ambiente passa a ser coletivo (interatividade), com possibilidade de ser multilinearizado e multisequencial, característica da hipertextualidade, e pode apresentar diversos recursos multimodais. Tais aspectos são utilizados pelos internautas, ao criarem seus textos nas redes sociais. Diante disso, recorremos aos estudos de Jubran ([2006] 1992); Brown e Yule (1983); Pinheiro (2006); Lins (2006) e Oliveira (2019) para identificar os conceitos basilares do tópico discursivo a fim de compreender os desafios dos textos produzidos nestes novos espaços de interação. Palavras-chave: Linguística Textual. Tópico discursivo. Facebook.

Abstract: This work aims to observe how the discursive topic acts in the new contexts internet interaction. The text in this environment becomes collective (interactivity) with the possibility of being multilinear and multisequential, a characteristic of hypertextuality, and can present several multimodal resources. Internet users utilize some specific aspects when they create their texts on social network. Therefore, we resort to Jubran's concepts ([2006] 1992); Brown and Yule (1983); Pinheiro (2006); Lins (2006) and Oliveira (2019) to identify the basic concepts of the

\footnotetext{
É doutora e mestre em Linguística pela Universidade Federal do Espírito Santo (UFES). http://orcid.org/o00o-0003-4973-7129

${ }^{* *}$ Professora adjunta da Universidade Federal do Espírito Santo (UFES). É doutora em Linguística pela Universidade Federal do Rio de Janeiro (UFRJ) com pós-doutorado em Linguística pela UNICAMP. http://orcid.org/oooo-0002-2192-7791

*** Doutor em Língua Portuguesa pela PUC de São Paulo. É professor do Departamento de Línguas e Letras e do Programa de Pós-Graduação em Linguística da Universidade Federal do Espírito Santo (UFES). http://orcid.org/0000-0002-3731-7613

${ }_{* * * \star}$ Mestre em Estudos Linguísticos pela Universidade Federal do Espírito Santo (UFES). Atualmente é professora de Inglês da Prefeitura Municipal de Vila Velha e professora de Língua Portuguesa na Secretaria de Estado do Espírito Santo. http://orcid.org/0ooo-0002-8492-9540

${ }_{* * * * *}$ Mestre em Estudos Linguísticos da Universidade Federal do Espírito Santo (UFES) e tutora no curso de Licenciatura em Letras Português do Instituto Federal do Espírito Santo (IFES), na modalidade a distância. http://orcid.org/00oo-0003-0305-7187
}

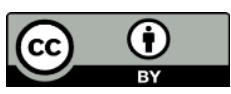

Este artigo está licenciado sob forma de uma licença Creative Commons Atribuição 4.0 Internacional, que permite uso irrestrito, distribuição e reprodução em qualquer meio, desde que a publicação original seja corretamente citada. https://creativecommons.org/licenses/by/4.0/deed.pt_BR. 
discursive topic in order to understand the challenges of these texts produced in these new spaces of interaction.

Keywords: Textual Linguistics. Discursive Topic. Facebook.

Resumen: El objetivo de este trabajo es observar cómo se puede ver el tema discursivo en los nuevos contextos de interacción en Internet. El texto se convierte en colectivo (interactividad), con la posibilidad de ser multilineal y multisecuencial, característico de la hipertextualidad. Dichos aspectos son utilizados por los usuarios de Internet cuando crean sus textos en las redes sociales. En vista de esto, recurrimos a los estudios de Jubran ([2006] 1992); Brown y Yule (1983); Lins (2006) y Oliveira (2019) que identifican los conceptos básicos del tema discursivo para comprender los desafíos de los textos de nuevos espacios de interacción.

Palabras Clave: Lingüística Textual. Tema discursivo. Facebook.

\section{Considerações iniciais}

As redes sociais trouxeram mudanças na forma como os internautas se relacionam não apenas com o texto, mas com a sociedade em geral, dando voz e visibilidade a quem estava invisível. $\mathrm{O}$ contexto digital aproxima as pessoas fazendo com que se achem no mesmo patamar. Conceitos como multimodalidade, hipertextualidade e intertextualidade são elementos que compõem este cenário e contribuem para que as informações sejam disseminadas virtualmente, criando um ambiente propício à interação.

Dessa forma, vemos que a participação ativa dos usuários nesses novos ambientes proporciona várias situações de interação, e os textos são produzidos com uma rapidez alarmante. Eles assumem características próprias do ambiente, isto é, "à medida que as práticas sociais das pessoas se mudaram para o âmbito online, muitos textos em nossa vida contemporânea fizeram o mesmo e assumiram diversas propriedades" (BARTON \& LEE, 2015, p. 42).

Levando em conta esses novos contextos de interações online, podemos falar em produções hipertextuais, as quais, nos primeiros trabalhos da Linguística Textual (doravante LT) brasileira, eram apresentadas como formas de composições textuais que faziam 
[...] do leitor simultaneamente co-autor do texto final. O hipertexto caracterizase, pois, como um processo de escritura/leitura eletrônica multilinearizado, multisequencial e indeterminado, que, segundo Bolter (1991:10), introduz um novo 'espaço de escrita', que ele caracteriza como 'escrita eletrônica', tendo em vista a tecnologia de base. (MARCUSCHI, 1999, p. 1, grifo nosso).

Nessa visão, essa "escrita eletrônica", ainda, é baseada em uma tecnologia disponibilizada, por links que construíam os sentidos de forma fluída e reconfigurável. Essas ações de coautoria, ainda, são unilaterais e indeterminadas, à vista disso essa concepção, não satisfaz os modos de análise dos espaços virtuais, pois vemos esses textos como eventos singulares, com começo, meio e fim.

Dessa definição, nos interessa observar, principalmente, o hipertexto como uma escrita cooperativa e fundamentada na participação de um leitor-construtor de sentidos, em um ambiente tecnológico. Mais recentemente, Paveau (2017) diz que a noção de hipertexto já está bem instalada, descrita e analisada, desde os anos de 1990. Segundo a autora, há três "famílias de hipertexto":

1. Como fragmentos digitalizados (anos 60-70), estocados e relacionados por um sistema de links;

2. Um elemento gerado pela máquina (anos 80-90), num processo em que a memória artificial se relaciona com a inteligência humana;

3. Parte das atividades humanas (desde os anos 2000).

Para a autora, a definição atual de hipertexto, ainda, se apoia na noção de link e de não lineariedade, mas ela adota, também, a visão de uma coconstrução do sentido, que é produzido pelo usuário e vai além de simplesmente clicar em links. Paveau (2017) aborda os recursos tecnológicos, para trazer uma descrição tecnodiscursiva do hipertexto. E garante que 
devemos adotar uma perspectiva que considere os usos, isto é, os processos tecnolinguísticos de elaboração, na produção como na recepção, uma vez que os dois se fundem. A descrição do hipertexto é baseada principalmente nas noções de link (a relacionalidade dos enunciados no contexto hipertextual), de não-linearidade e/ou descontinuidade (a concepção do texto como uma relação dinâmica de fragmentos) e de escrituleitura (coconstrução de significado pelo usuário em um duplo gesto de leitura e escrita) (PAVEAU, 2017, p. 214). ${ }^{1}$

A visão de como os usuários constroem seus textos num processo em que a leitura e a escrita se fundem, chamado pela autora de escrituleitura, corrobora com as ações dos usuários das redes sociais ao lerem os comentários e ao elaborarem suas produções, quase ao mesmo tempo.

Paveau (2017) considera o link como "uma dimensão importante da escrita hipertextual, contribuindo para a forma de enunciados, a elaboração de seu significado e seu modo de circulação". Para ela, o hipertexto se tornou um texto híbrido, pois é formado por vários recursos e não só de links. E “como esses links são estabelecidos por meio de dispositivos técnicos, devemos adotar uma abordagem de hipertexto como um compósito" (PAVEAU, 2017, p. 215)².

Dessa forma, trazemos um novo olhar para os hipertextos que surgem, nas redes sociais virtuais, ou seja, como eventos que se constroem pelas diversas conexões e interações entre os usuários de um ambiente virtual.

De acordo com Elias e Cavalcante (2017, p. 321), o hipertexto é um “constructo caracterizado pelos traços de conexão múltipla entre textos [...] resultante da

\footnotetext{
${ }^{1}$ Tradução da autora para: "Pour fournir une description technodiscursive de l'hypertexte, il faut adopter une perspective qui prend en compte les usages, c'est-à dire les processus technolinguistiques d'élaboration, en production comme en réception puisque les deux se confondent. La description de l'hypertexte s'appuie principalement sur les notions de lien (la relationalité des énoncés en contexte hypertextuel), de non-linéarité et ou discontinuité (la conception du texte comme mise en relation dynamique de fragments) et d'écrilecture (coconstruction du sens par l'usager dans un geste double de lecture et d'écriture)".

${ }^{2}$ Tradução da autora para: "Ces liens étant établis via les dispositifs techniques, il faut donc adopter une approche de l'hypertexte comme composite". e "une dimension majeure de l'écriture hypertextuelle, en contribuant à la forme des énoncés, l'élaboration de leur sens et leur mode de circulation”.
} 
participação e do trabalho realizado colaborativamente por usuários em interação online."

Na esteira dessa discussão, Lima (2019) afirma que o contexto digital aproxima as pessoas, fazendo com que se achem no mesmo patamar. Além disso, “a multimodalidade, a hipertextualidade e intertextualidade são elementos que compõem este cenário contribuem para que as informações sejam disseminadas virtualmente criando um ambiente de convergência e aumento de fluxos de informação" (LIMA, 2019, p.6o).

Nesse contexto, o conceito de tópico, inicialmente proposto por Jubran (2002) como uma unidade de análise discursiva em uma organização de natureza tópica oral prototípica, se estende além do turno dado a cada falante. Marcuschi (2007) destaca que a unidade central organizacional discursiva acontece diante: "daquilo que o falante faz ou diz enquanto tem a palavra, incluindo aí a possibilidade de silêncio" ou ainda, percebido por Jubran et al. (2002), quando em uma conversação ocorre uma relação de interdependência entre os turnos.

Pode ser movida pela preocupação dos falantes se entrosarem, procurando manter a conversação em torno de um conjunto de referentes comuns. [...] Nesse caso são observáveis segmentos discursivos articulados em torno de um tópico proeminente (JUBRAN et al., 2002, p. 342).

Já Lins (2008) destaca que toda sequência conversacional é tópica, semântica e pragmaticamente relevante. Assim, todo "bloco" de conversa é percebido como coerente, ou seja, há uma continuidade durante o diálogo que proporciona uma relação lógica. Igualmente, é necessário enfatizar que a falta dessa logicidade não acarreta, necessariamente, uma incoerência, sendo este o elo que vai organizar, identificar e motivar o texto falado a partir de segmentos textuais.

De certo, é de suma importância compreender o conceito de tópico discursivo abordado pela Linguística Textual, a fim de entender como a construção tópica é desenvolvida nos novos contextos interativos. 


\section{Linguística Textual e noção de tópico discursivo}

Tópico discursivo não é um assunto novo, pois há vários estudos que abordam essa temática, como o Projeto de Gramática do Português falado (PGPF), que analisa a topicalidade em textos falados. Destacamos também os trabalhos de Lins (2006) que demonstram como que o tópico discursivo pode ser analisado não apenas em textos orais, mas também em textos multimodais, como os quadrinhos, reforçando, assim, a noção de Tannen (1985) sobre um continuum nas relações fala/escrita, ou seja, os quadrinhos utilizam a linguagem escrita, mas apresentam características da oralidade, pois há um “caráter de informalidade, o que propicia uma análise da organização tópica desse gênero textual, tendo como ponto de partida o modelo utilizado para estudar textos falados" (LINS, 2006, p. 3). A linguista esclarece que

essa dubiedade do texto de quadrinhos decorre do fato de que ele é, por natureza de produção, um texto escrito; mas, por natureza de recepção, oral. Esse objetivo de mostrar-se um texto falado verifica-se pela organização de tópicos discursivos e, também, pela característica de ser dialogado e construído em linguagem informal (LINS, 2006,p.8).

No gênero estudado pela autora, é possível perceber que há dois códigos (verbal e visual) que se completam e, neles, os diálogos são produzidos de forma semelhante ao processo interativo, em que os personagens "planejam" suas falas de acordo com o fluxo interacional, no entanto nossa proposta é investigar como o tópico discursivo é construído, mantido, ampliado e rompido nas interações virtuais.

A investigação do tópico discursivo, nos últimos tempos, ganhou muito destaque na LT, de tendência sociocognitiva interacional, e o tópico é considerado objeto fundamental na estruturação dos textos. Para Pinheiro (2006), o tópico é uma categoria interacional e se identifica com os interesses de seus usuários. Segundo o autor, 
O tópico, portanto, se identifica com a questão de interesse imediato, serve para descrever o conteúdo sobre o qual se fala/escreve e sinaliza a perspectiva focalizada. Nesse sentido ele é visto como uma categoria analítica, de base textual-discursiva, ou seja, relaciona-se ao plano global de organização do texto. Mas é também uma categoria interacional, pois é resultante da natureza interativa e colaborativa do discurso (PINHEIRO, 2006, p. 44).

Para fins de análise, Jubran et al. (1992; 2006) propõem a assimilação de duas propriedades do tópico discursivo: a centração, originada de contribuições conversacionais para um assunto relevante, e organicidade, motivada a partir da “organização dos tópicos no texto, em termos de sequenciação e de variáveis graus de detalhamento que eles comportam nas manifestações verbais" (JUBRAN, 2006, p. 3).

1. A centração é o inter-relacionamento entre as unidades do texto, que convergem para o tópico central, isto é, o "assunto" ao que todos os demais se relacionam. Na concentração de determinado assunto o tópico abrange os traços de concernência, relevância e pontualização. Grosso modo, na concernência usufruímos de uma relação entre os elementos textuais, ao integrar referentes explícitos ou inferíveis do texto; na relevância os elementos textuais são delineados como os focais, no texto e na pontualização ocorre a localização desses conjuntos em determinado ponto do texto. Esses aspectos são muito importantes, pois conferem "à categoria de tópico discursivo critérios para o reconhecimento do estatuto tópico de um fragmento textual" (JUBRAN, 2006, p. 35). A propriedade da centração define uma unidade concreta para a análise, já que o tópico discursivo é considerado uma categoria abstrata. Logo, observar a centração de um texto é um princípio muito valioso para a conservação do tópico em todo sua produção.

2. A organicidade, segundo a mesma autora, se manifesta por meio de relações de interdependência tópica e intratópica estabelecidas, de forma simultânea, em dois planos: o hierárquico ou vertical, conforme as dependências de tópicos que se implicam e o plano linear ou sequencial que é a articulação tópica que sucede por 
meio de interposições de tópicos caracterizados por continuidade tópica (organização sequencial) e descontinuidade tópica (interrupção sequencial). No princípio da organicidade, o processo de articulação tópica promove a progressão do tópico por meio da continuidade tópica que pode ser caracterizada pela relação de proximidade entre dois tópicos.

Nesse sentido, o texto não é visto mais como algo pronto ou como um produto que pressupõe uma compreensão passiva em que o interlocutor, simplesmente, decodifica os elementos de sua materialidade linguística. Na verdade, ele vem sendo concebido como um processo sociocognitivo criativo, cujos sentidos são construídos durante a interação. Marcuschi (2008) defende uma noção de texto formado de múltiplas participações, em diferentes práticas discursivas as quais transcendem o funcionamento de regras fixas, isto é, “[...] o texto se dá como um ato de comunicação unificado num complexo universo de ações alternativas e colaborativas" (MARCUSCHI, 2008, p. 79).

Para o autor o texto não é um produto, mas um evento, cuja sua existência depende do processamento feito por alguém em algum contexto. Logo, seus traços característicos dependem da realização sociodiscursiva, conduzidas cognitivamente e não dos fatores intrínsecos. Tudo isso faz o texto ser "plástico" capaz de ser reproduzido e renovado, de acordo com a situação comunicativa de seus participantes.

Diante disso, precisamos levar em consideração de que o tópico discursivo vai além do assunto a ser tratado dentro de uma interação, pois nos ambientes digitais "há uma constante flutuação de tópicos discursivos e essa flutuação não é tido ou sentido como incoerente porque, durante a evolução natural de um diálogo, os tópicos têm uma série de relevâncias que podem ser detectadas e selecionadas pelos falantes" (FÁVERO, 2010, p. 59). No exemplo a seguir, podemos verificar essa flutuação de assuntos sendo discutidos ao longo da interação: 
Figura 1: Ponte interditada

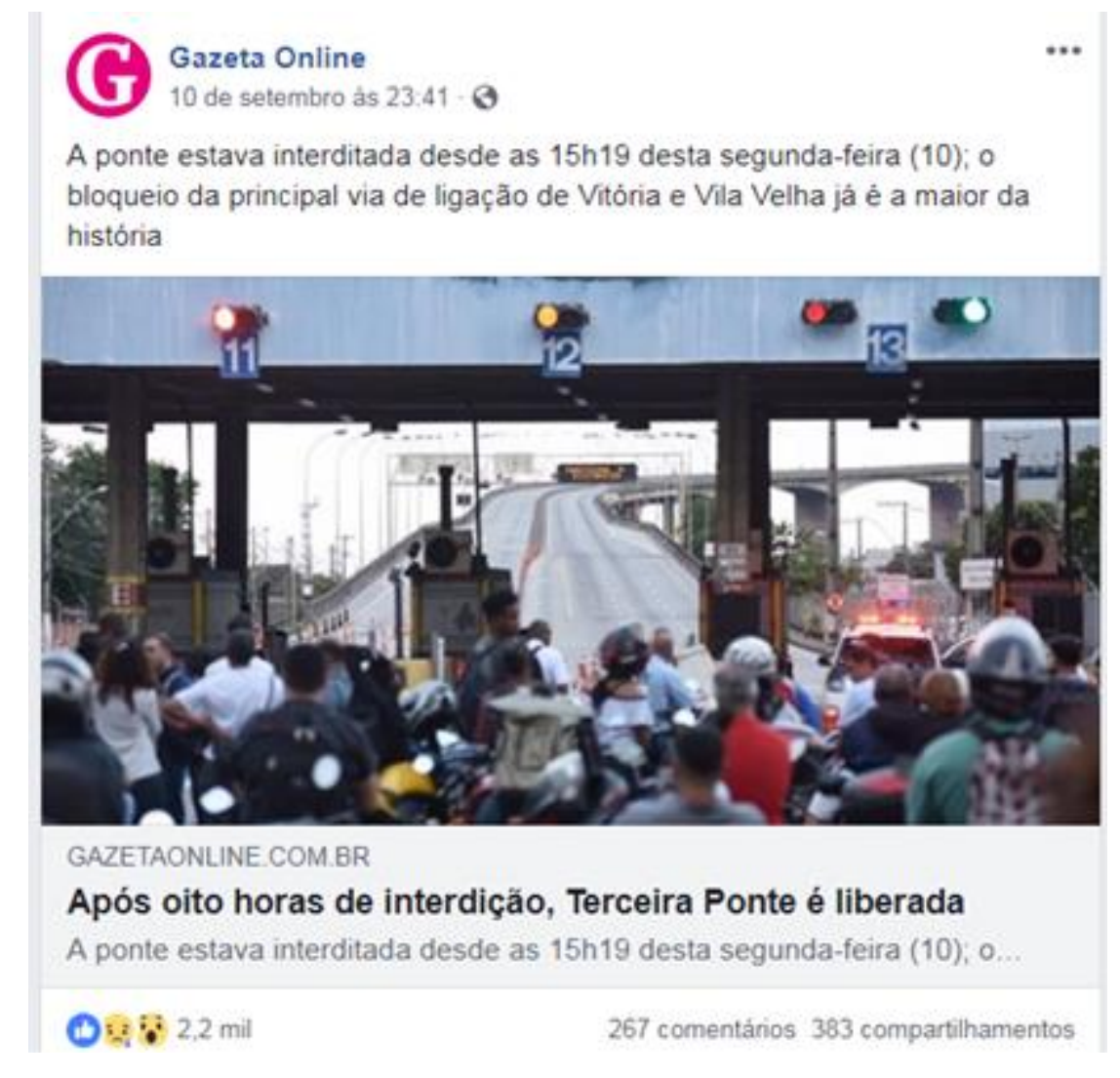

Fonte: https://www.facebook.com/gazetaonline/posts/2140807189276258

A Terceira Ponte é um dos acessos que liga Vila Velha a Vitória. Em dias normais há grande circulação de veículos.Em horários de pico, há engarrafamentos e longas filas. No dia 10 de setembro de 2018, o acesso à Terceira Ponte foi bloqueado por oito horas, devido a uma operação para resgatar alguém que estava tentando se suicidar. $\mathrm{O}$ trânsito ficou caótico tanto em Vitória quanto em Vila Velha, chegando a afetar municípios circunvizinhos.

O supertópico dessa interação é a tentativa de suicídio na $3^{\text {a }}$ ponte e os 5 subtópicos são: 


\section{Sbt 1- Favoráveis à interdição}

\begin{tabular}{l}
\hline Fiquei tão feliz em saber nos comentários que não \\
houve o suicídio.Ontem inclusive era o dia nacional do suicídio! \\
Mas não houve comemoração por uma situacao que nem deveria \\
ter data específica!! \\
A vida sorriu outra vez! \\
Curtir - Responder - $25 \mathrm{sem}$ - Editado
\end{tabular}

\section{Sbt 2- Contrários à interdição}

Agora o pessoal tem que se juntar e processar, não tem cabimento a ponte ficar fechada por tanto tempo.

Curtir - Responder - 25 sem

\section{Sbt 3- Mobilidade urbana}

Como falei num post antes: Sabe o que isso quer dizer? Que a cidade precisa evoluir quando se trata de transporte público.

Cadê os projetos das barcas?

Quer ser cidade grande pensando pequeno.

Curtir - Responder - 25 sem

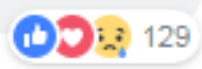

\section{Sbt 4- Redes de proteção}

Alguém parou pra pensar, que pode ter sido estratégia de marketing, e pressão pq já foi apresentado o projeto da rede de proteção, e nada se foi feito, por que é muito estranho 8 horas de ponte interditada? Quem quer se matar de verdade pularia logo, ou ficaria cansado e desceria de lá, ou por coincidência aconteceu mesmo! Mas que é estranho isso é! Um caso a ser analisado..... mas que bom que o rapaz saiu de la...

Curtir - Responder - 25 sem 
Sbt 5- Comentário do internauta W.T

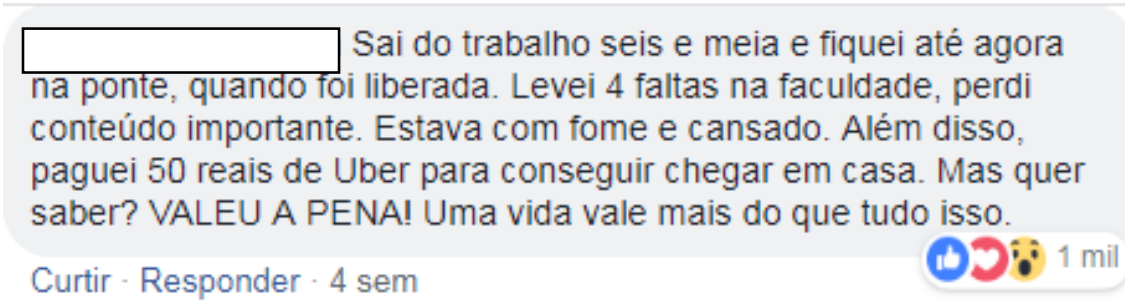

Percebemos que há um supertópico que motiva os internautas a discutirem sobre algum assunto e, ao longo do processo interativo, surgem subtópicos que proporcionam a progressão tópica. A respeito disso, Oliveira (2019) afirma que

\footnotetext{
Compreendemos que os subtópicos possuem o que Elias e Cavalcante definem como "conexão múltipla entre blocos de significado" (ELIAS; CAVALCANTE, 2017:320), ou seja, os comentários se agrupam em blocos de significado que dialogam entre si, conectando-se e possibilitando a progressão tópica (OLIVEIRA, 2019, p. 348)
}

Dessa forma, compreendemos que as interações do Facebook apresentam as categorias definidoras do tópico discursivo: centração e organicidade. A primeira categoria é percebida ao verificar que os tópicos e os subtópicos apresentam uma interdependência semântica, focal e interativa, já a segunda é identificada ao "observar que os comentários estabelecem interdependência no plano sequencial (horizontal) e hierárquico (vertical)" (OLIVEIRA, 2019. p. 349).

O alargamento da noção do tópico, em textos digitais, favorece a relação intertópicos, o que dirige no sentido de uma ampliação do assunto em desenvolvimento, que vai gerar argumentatividade, a fim de levar o interlocutor a modificar sua opinião ou concordar com o tema discutido. 


\section{Critérios analíticos usados para o trabalho com o tópico discursivo}

A definição de tópico discursivo é estabelecida para Brown e Yule (1983), como sendo "aquilo sobre o que está falando", é o assunto sobre o qual se está pronunciando e muitas vezes há expressões no discurso que ajudam a identificar o tópico, como "Era uma vez... e eles viveram felizes para sempre” "Você já ouviu falar sobre...?” ou “O que é o que é....” e outras formas que podem ser usadas para marcar o início de uma piada ou anedota.

Os autores inovam ao examinar os usos do termo "tópico" no discurso e a sua relação com a relevância e a coerência. Também inovam ao considerar como a noção de tópico se relaciona com a representação do conteúdo do discurso. Sobre a relação do tópico com a relevância, eles afirmam que o termo "relevância" na análise da conversação é derivado das máximas conversacionais propostas por Grice (1975), que prevê que há um acordo cooperativo entre os participantes da conversação. Esse acordo é definido com as seguintes máximas: qualidade, quantidade, relevância e modo.

Pela primeira máxima, pressupõe-se que tudo que o interlocutor diz é verdadeiro; pela segunda, que ele só diz o necessário; pela terceira, que só diz o que é pertinente para aquela comunicação e, por fim, pela quarta máxima mostra que o falante deve fazer a comunicação do melhor modo possível. Já acerca da coerência, os autores informam que o sentido é essencial para compreensão tópica.

Nas interações, sejam virtuais ou sejam físicas, buscamos estabelecer diálogo com o interlocutor, pois, segundo Jubran (2015) "a conversação implica uma construção colaborativa" (JUBRAN, 2015, p. 85). Nesse contexto, o texto emerge graças à interação com os outros, de acordo com ideologias e contextos variados (o lugar, o tempo, as circunstâncias materiais e sociais, os destinatários, ou seja, os possíveis leitores), "configurando, assim, a dimensão polifônica do texto, em que ganham especial relevo os contextos partilhados que permitem e estimulam a interação e a comunicação" (SEARA, 2015, p. 79). 
Assim, de acordo com Oliveira (2019) o texto começa com a postagem inicial e vai sendo construído pelos interlocutores a cada novo comentário, podendo ser retomado em qualquer tempo, inclusive, por outros usuários que não estavam participando da interação inicial. Por isso que focalizamos o texto "como uma interação de estratégias, em que cada um deve reconhecer o papel do outro - não há locutor sem interlocutor e vice-versa -, podemos concluir que o contrato de comunicação textual exige negociação, cumplicidade" (PAULIUKONIS; CAVALCANTE, 2018, p. 30 ).

Desse modo, ao interagir com o outro, buscamos ser cooperativos para que o interlocutor possa compreender e fazer parte do processo interativo, pois procuramos construímos juntos um discurso mais ou menos coerente, "os participantes da troca comunicativa constroem entre si um certo tipo de relação (de distância ou de proximidade, de hierarquia ou de igualdade, de conflito ou de conivência), que não pára de evoluir ao longo da interação" (KERBRAT-ORECCHIONI, 2005, p.83).

Dessa forma, levando em conta o processo interativo nos novos textos interacionais digitais, as propriedades definidoras da categoria tópico poderiam ser as de centrações, pois o texto é visto como uma rede de nós conectados, que de acordo com Oliveira (2019) “todos esses nós se conectam em rede, formando uma cadeia temática, possíveis de serem identificados, por meio dos referentes tópicos" (OLIVEIRA, 2019, p.112).

Percebemos que as centrações são representadas pelos vários fios condutores nos textos da mídia que podem apresentar uma interligação na medida que a escolha de links não é aleatória, uma vez que o texto é visto como uma rede de nós conectados. Assim, as escolhas de leitura ou de participação direta por meio de postagem de textos ou por meio de recursos imagéticos digitais estão relacionados a cada nó dessa rede que mantém todos interligados.

Os comentários permitem o enquadramento dos tópicos e pelos processos referenciais os usuários inserem suas opiniões no contexto compartilhado que se cria no momento da interação do espaço virtual. 


\section{Desafios dos textos da mídia internet na análise textual do tópico discursivo}

A expansão das tecnologias da informação e da comunicação vem transformando a vida em sociedade e alterando nossa relação com os textos. Com isso, percebemos grandes e rápidas mudanças tanto na forma de interação quanto na forma de comunicação. Podemos notar uma consequência dessas mudanças na prática de leitura, com a emergência de textos híbridos, presentes no ambiente virtual, que têm a tela como principal suporte, exigindo conhecimentos que ultrapassam a fronteira do texto impresso.

O aparecimento desses textos nas redes sociais, como o Facebook, implica transformações no processo de criação e de recepção de textos, uma vez que exploram aspectos como a multimodalidade, a hipertextualidade e a interatividade. Essas formas de interação demandam habilidades de leitura e de produção específicas e, consequentemente, exigem uma formação mais específica dos interagentes, porque, diante da tela, o usuário/leitor precisa compreender a função dos links, identificar ícones e signos próprios do gênero, como curtir e comentar, que fazem parte do Facebook. A respeito disso, Lima (2019) aborda que

a hipertextualidade é considerada inovadora por criar um novo modelo de produção de texto com a utilização da tecnologia que consegue efetivamente juntar elementos diversos. É a apresentação clara e direta de bons argumentos em um texto que independente da forma que se apresenta sempre será um texto usado de forma diferente a partir do público que acessa a informação, e com isto, altera- o de forma que melhor lhe convém ( LIMA, 2019, p. 6o)

A ampliação dos modos comunicacionais, principalmente, aqueles que surgiram no processo de consolidação da tecnologia, estabeleceram novos modelos de leitura e produção. Não basta ler, é preciso ligar a palavra às imagens, fazendo com que todos os “[...] recursos utilizados na construção dos gêneros textuais exerçam uma função retórica 
na construção de sentidos dos textos" (DIONÍSIO, 2005, p. 32).

Esse uso constante das redes sociais e comunidades virtuais proporcionam uma renovação no texto, pois a forma de explorá-lo requer uma leitura não linear, já que são compostos de recursos multimodais. Em relação a isso, Dionísio (2005) afirma que

cada vez mais se observa a combinação de material visual com a escrita; vivemos, sem dúvida, numa sociedade cada vez mais visual. Representação e imagens não são meramente formas de expressão para divulgação de informações, ou representações naturais, mas são, acima de tudo, textos especialmente construídos que revelam as nossas relações com a sociedade e com o que a sociedade representa. (DIONÍSIO, 2005, p. 16o)

A linguagem utilizada no mundo digital privilegia modalidades diferentes da escrita, uma vez que os textos usados nas comunicações digitais são repletos de ícones, como os emojis e emotions, cores que exploram diferentes fontes e layouts com diversos hiperlinks que direcionam o leitor a novos textos.

Ancorados nos postulados de Marcuschi (2010 [2002]), observamos que os gêneros contidos no ambiente virtual proporcionam impacto na linguagem e na vida social, pois os ambientes virtuais são versáteis e competem, em importância, entre as atividades comunicativas, ao lado do papel e do som. O autor revela três aspectos relevantes para análise desses gêneros:

(1) Seu franco desenvolvimento e um uso cada vez mais generalizado;

(2) Suas peculiaridades formais e funcionais, não obstante terem eles contrapartes em gêneros prévios;

(3) A possibilidade que oferecem de se rever conceitos tradicionais, permitindo repensar nossa relação com a oralidade e a escrita (MARCUSCHI, (2010[2002]): 25).

Atendendo a esses aspectos, percebemos que nesses gêneros há a presença constante da hipertextualidade, da multimodalidade e da interatividade. 


\section{Considerações finais}

A tecnologia trouxe uma forma de comunicação extremamente versátil, com normas próprias em que o conceito do errado é revisto, pois a rapidez com que se dissemina não permite correções. Uma das principais características é o uso de abreviações que pode ser utilizada, em especial pela juventude, às vezes de forma passageira, ou seja, "sob o impacto das novas formas de tecnologias", presenciamos uma nova situação que "está desconstruindo toda a oposição entre a fala e a escrita” conforme dito por Halliday (1996, p.354).

Considerando que, no ambiente virtual, "todos os escritos mantêm de alguma forma laços ainda que distantes entre si” (XAVIER, 2013, p.162), por meio das ações hipertextuais as ideias dos usuários são conectadas e novos textos são escritos. Eles focalizam uma nova centração do tópico, mas, durante as interações, não perdem o foco no tópico central.

É perceptível que com toda essa disseminação das redes sociais, o texto vem adquirindo novas características e o conceito de alargamento tópico é proveniente desse ambiente, pois os usuários podem interagir a partir dos diferentes nós que conectam os textos.

Oliveira (2019) afirma que "as novas mídias, o ciberespaço, as hipermídias, o hipertexto interferem como novas linguagens no sujeito contemporâneo e na estruturação do pensamento, que vem se tornando cada vez mais heterogênea e não linear" (OLIVEIRA, 2019, p.91). Desse modo,

[...] a produção textual em ambiente de rede solicita dos estudiosos e analistas de textos um olhar atualizado sobre práticas textuais e interacionais empiricamente realizadas nesses novos contextos, bem como sobre modelos teóricos de descrição e análise para que sejam capazes de dar conta da integração de diferentes linguagens no quadro dos diversos sistemas de conhecimento dos sujeitos em situação de interação. (CAPISTRANO JÚNIOR, ELIAS, LINS, NEGREIROS, LIMA, 2019) 
Em relação ao tópico discursivo nos novos contextos de interação, verificamos que conforme Brown \& Yule (1983), o tópico está relacionado a representações de conteúdo, organizado de forma hierárquica, sendo dividido em um supertópico que pode ser entendido como um assunto sobre o que se está falando e os subtópicos, com seus segmentos tópicos que demonstram o processo interativo dos participantes.

Além disso, "há também a delimitação local, que mostra que, geralmente, o tópico tem início, desenvolvimento e fim, mas essas marcas nem sempre são evidentes, podendo aparecer marcadores conversacionais, elementos prosódicos (pausas, hesitações), perguntas, repetições, paráfrases etc" (FÁVERO; ANDRADE; AQUINO, 2000, p. 39) e no caso das redes sociais, essa delimitação local poderá não ter um fim determinado, já que outros usuários podem comentar uma postagem em qualquer data e iniciar uma nova interação comunicativa.

\section{Referências}

BARTON, David; LEE Carmen. Linguagem online: textos e práticas digitais. São Paulo: Parábola Editorial, 2015.

BROWN, Gillian \& YULE, George. Discourse analysis. Cambridge: Cambridge University Press, 1983. Pp. xii + 288. - M. Stubbs, Discourse analysis. Oxford: Basil Blackwell, 1983. Pp. xiv +272.

CAPISTRANO JÚNIOR, Rivaldo; ELIAS, Vanda Maria; LINS, Maria da Penha; NEGREIROS, GIL; LIMA, Geralda de Oliveira Santos. Organização tópica na interação em rede: aspectos textuais, contextuais e de coerência. Revista (Con)Textos Linguísticos, v. 13, n. 25. p. 159-180, 2019. Disponível em:< https://periodicos.ufes.br/contextoslinguisticos/article/view/27886>. Acesso em: 28 fev. 2020. 
DIONISIO, Ângela Paiva. Gêneros multimodais e multiletramento. In: Acir Karwoski; Beatriz Gaydeczka; Karim Brito (Orgs.). Gêneros textuais: reflexões e ensino. Palmas e união da Vitoria, PR: Kaygangue, 2005.

ELIAS, Vanda Maria da Silva; CAVALCANTE Mônica Magalhães. Linguística Textual e estudos do hipertexto: focalizando o contexto e a coerência. In: CAPISTRANO JUNIOR, Rivaldo; LINS, Maria da Penha Pereira; ELIAS, Vanda Maria (Orgs.). Linguística Textual: diálogos interdisciplinares. 1ed. São Paulo: Labrador, 2017. p. 317- 338.

FÁVERO, Leonor Lopes; ANDRADE, Maria Lúcia da Cunha Victória de Oliveira; AQUINO, Zilda Gaspar Oliveira de. Oralidade e escrita: perspectiva para o ensino de língua materna. São Paulo: Cortez, 2000.

.O tópico discursivo. In: PRETI, Dino (org). Análise de textos orais. São Paulo: Humanitas, 2010.

A correção do texto falado: tipos, funções e marcas. In: NEVES, M. H. de M (org.). Gramática do português falado, vol. VII, São Paulo: Humanitas/FFLCH/USP, Campinas/SP: Editora da Unicamp. 1999.

GRICE, Herbert Paul. Meaning. Philosophical Review, 66: p. 377-388, 1957. Logic and Conversation. In: P. Cole and J. Morgan (ed.), Pragmatics (Syntax and Semantics), vol. 9, Nova York: Academic Press, 1975.

HALLIDAY, Michael Alexander Kirkwood. Literacy and linguistics: a functional perspective. In: HASAN, Ruquaiya; WILLIAMS, Geof (eds). Literacy in Society. London and New York: Longman, 1996. p. 339-376.

JUBRAN, Clélia Cândida Abreu Spinardi. Tópico discursivo. In: JUBRAN Clélia Cândida Abreu Spinardi e KOCH Ingedore Grunfeld Villaça (Orgs.). Gramática do Português Culto Falado no Brasil: Construção do texto falado, vol. I. Campinas/SP: UNICAMP, 2006. p. 89-132.

Tópico discursivo. In: JUBRAN, Clélia Spinardi (Org.) A construção do texto falado. São Paulo: Contexto, 2015.

. Organização tópica da conversação. In: Ilari Rodolfo (Org.). Gramática do Português Falado. Campinas: UNICAMP; São Paulo: FAPESP, V.2, 1992. 
Tópico discursivo. Em: Clélia Cândida Abreu Spinardi Jubran e Ingedore Grunfeld Villaça Koch (Orgs.). Gramática do Português Culto Falado no Brasil. Campinas: Editora da UNICAMP, vol. I - Construção do texto falado, 2002.

- Revisitando a noção de tópico discursivo. 2006 Disponível em: http://revistas.iel.unicamp.br/index.php/cel/article/viewFile/1541/1113. Acesso em o6 de junho de 2017.

LIMA, Aline Souza de. Referenciação e humor em memes do perfil Dilma Bolada do Facebook. PPGEL: UFES: Dissertação de mestrado. 2019.

LINS, Maria da Penha Pereira. Mas, afinal, o que é mesmo Pragmática? In: Fala Palavra, n.2, outubro 2002 .

. Organização tópica do discurso de tiras diárias de quadrinhos. Universidade Federal do Rio de Janeiro. Tese de doutorado. 2004.

. O tópico discursivo em textos de quadrinhos. Vitória: EDUFES, 2008.

MARCUSCHI Luiz Antonio. Linearização, Cognição e Referência: o desafio do Hipertexto. Comunicação apresentada no IV Colóquio da Associação Latino Americana de Análise do Discurso, Santiago, Chile, 5 a 9 de abril de 1999. Disponível em: <http://Web.uchile.cl/facultades/filosofia/Editorial/libros/discurso_cam bio/17Marcus.pdf>. Último acesso em: 28 jun. 2018.

. Produção Textual, análise de gênero e compreensão. São Paulo: Parábola Editorial, 2008.

- Gêneros textuais emergentes no contexto da tecnologia digital. In: MARCUSCHI, L. A.; XAVIER, A. C. (Org.). Hipertexto e gêneros digitais: novas formas de construção do sentido. Rio de Janeiro: Lucerna, 2004. p. 13-67.

OLIVEIRA, Mônica Lopes Smiderle. Construção tópica e mecanismo de (im) polidez em interações do Facebook: uma análise pragmática dos recursos imagéticos digitais. UFES:PPGEL. Tese de doutorado. 2019.

PAULIUKONIS, Maria Aparecida Lino; CAVALCANTE, Mônica Magalhães. Texto e Ensino. Natal: SEDIS- UFRN, 2018.

PAVEAU, Marie-Anne. L'analyse du discours numérique: Dictionnaire des formes et des pratiques. Paris, Editions Hermann, 2017. 
PINHEIRO, Clemilton Lopes. O tópico discursivo como categoria analítica textualinterativa. Cadernos de Estudos Linguísticos, Campinas v. 48, n. 1, p. 43-52, 2006. Disponível em: < https://periodicos.sbu.unicamp.br/ojs/index.php/cel/article /view/8637254>. Último acesso em: 22 out. 2019.

SEARA, Isabel Roboredo. A escrita colaborativa em ambiente digital: a metáfora do labirinto. In: CABRAL, Ana Lúcia Tinoco; MARQUESI, Sueli Cristina (Orgs.). Leitura, Escrita e Tecnologias da Informação. São Paulo: Terracota 2015.

XAVIER, Antonio Carlos dos Santos. A era do hipertexto: linguagem e tecnologia. Recife: Pipa Comunicação, 2013.

Recebido em 02/03/2020. Aprovado em 14/o7/2020. 